Article

\title{
Electroplating of CdTe Thin Films from Cadmium Sulphate Precursor and Comparison of Layers Grown by 3-Electrode and 2-Electrode Systems
}

\author{
Imyhamy M. Dharmadasa ${ }^{1}$, Mohammad L. Madugu ${ }^{1, *}$, Olajide I. Olusola ${ }^{1}$, Obi K. Echendu ${ }^{2}$, \\ Fijay Fauzi ${ }^{3}$, Dahiru G. Diso ${ }^{4}$, Ajith R. Weerasinghe ${ }^{5}$, Thad Druffel ${ }^{6}$, Ruvini Dharmadasa ${ }^{6}$, \\ Brandon Lavery ${ }^{6}$, Jacek B. Jasinski ${ }^{6}$, Tatiana A. Krentsel ${ }^{6}$ and Gamini Sumanasekera ${ }^{6}$ \\ 1 Materials \& Engineering Research Institute, Faculty of Arts, Computing, Engineering and Sciences, \\ Sheffield Hallam University, Sheffield S1 1WB, UK; Dharme@shu.ac.uk (I.M.D.); \\ olajideibk@yahoo.com (O.I.O.) \\ 2 Physics Department, Federal University of Technology Owerri, Ihiagwa PMB 1526, Imo, Nigeria; \\ oechendu@yahoo.com \\ 3 School of Electrical System Engineering, University of Malaysia Perlis, Pauh Putra Campus, 02600 Arau, \\ Perlis, Malaysia; fijay@unimap.edu.my \\ 4 Kano University of Science and Technology, Wudil PMB 3244, Kano, Nigeria; dgdiso@yahoo.co.uk \\ 5 California State University, Fresno 2320 E. San Ramon Ave., Fresno, CA 93740, USA; ajithroshen@yahoo.com \\ 6 Conn Center for Renewable Energy Research, University of Louisville, Louisville, KY 40292, USA; \\ thad.druffel@louisville.edu (T.D.); ruvinid8@gmail.com (R.D.); brandon.lavery@louisville.edu (B.L.); \\ jbjasinski@gmail.com (J.B.J.); Tatiana.Krentsel@louisville.edu (T.A.K.); \\ gamini.sumanasekera@louisville.edu (G.S.) \\ * Correspondence: maduguu@yahoo.com; Tel.: +44-114-225-6910
}

Academic Editors: Massimo Innocenti and Alessandro Lavacchi

Received: 29 June 2016; Accepted: 19 January 2017; Published: 24 January 2017

\begin{abstract}
Electrodeposition of CdTe thin films was carried out from the late 1970s using the cadmium sulphate precursor. The solar energy group at Sheffield Hallam University has carried out a comprehensive study of CdTe thin films electroplated using cadmium sulfate, cadmium nitrate and cadmium chloride precursors, in order to select the best electrolyte. Some of these results have been published elsewhere, and this manuscript presents the summary of the results obtained on CdTe layers grown from cadmium sulphate precursor. In addition, this research program has been exploring the ways of eliminating the reference electrode, since this is a possible source of detrimental impurities, such as $\mathrm{K}^{+}$and $\mathrm{Ag}^{+}$for CdS/CdTe solar cells. This paper compares the results obtained from CdTe layers grown by three-electrode (3E) and two-electrode (2E) systems for their material properties and performance in CdS/CdTe devices. Thin films were characterized using a wide range of analytical techniques for their structural, morphological, optical and electrical properties. These layers have also been used in device structures; glass/FTO/CdS/CdTe/ $\mathrm{Au}$ and $\mathrm{CdTe}$ from both methods have produced solar cells to date with efficiencies in the region of 5\%-13\%. Comprehensive work carried out to date produced comparable and superior devices fabricated from materials grown using 2E system.
\end{abstract}

Keywords: electrodeposition; $\mathrm{CdTe} ; \mathrm{CdSO}_{4}$ precursor; solar energy materials; $\mathrm{CdS} / \mathrm{CdTe}$ solar cells

\section{Introduction}

Cadmium telluride (CdTe) thin films have received much attention due to their various applications in electronic devices, such as solar cells [1] and X- and $\gamma$-radiation detectors [2]. The increase in demand for clean and sustainable energy is a huge challenge for the photovoltaic 
(PV) community to develop low-cost and high efficiency solar panels. The present sources of energy, which are mostly from fossil fuel, are harmful to the sustainability of our ecosystem. Alternative technologies, such as photovoltaics (PV), which convert sunlight into clean energy, have been the main research focus at present [3]. The II-VI semiconductor materials have been found suitable in complementing this effort. Among these semiconductors, CdTe stands out to be one of the most researched and promising semiconductor materials in the production of both laboratory-scale and large area optoelectronic devices, such as the solar panels. CdTe has a direct and near ideal bandgap of $1.45 \mathrm{eV}$ for one bandgap and single $\mathrm{p}-\mathrm{n}$ junction solar cells with a high absorption coefficient $\left(>10^{4} \mathrm{~cm}^{-1}\right)$ [4]. CdTe can be $n$ - or p-type in electrical conduction $[5,6]$ depending on the stoichiometry or intentionally-added dopants. These are among the properties that make it a suitable material for application in solar energy conversion. CdTe can be grown using low-cost techniques, and the material can absorb over $90 \%$ of photons with energy greater than $E_{\mathrm{g}}=1.45 \mathrm{eV}$ using only about a $2.0 \mu \mathrm{m}$ thick layer.

CdTe thin films have been grown using a large number of deposition techniques [7]. Some of the main techniques used are close-spaced sublimation (CSS) [2], sintering [8], electrodeposition (ED) [1], molecular beam epitaxy (MBE) [9], metalorganic chemical vapor deposition (MOCVD) [10], pulsed laser deposition (PLD) [11], etc. Electrodeposition is a simple and low-cost technique and offers the advantage of growing materials with both n-type and p-type electrical conductivity by simply changing the growth potential using a single electrolytic bath, and it produces electronic device-quality films for solar cell fabrication.

In electrodeposition, CdTe can be cathodically synthesized using either aqueous $[1,12]$ or non-aqueous [13] electrolytes in acidic $(\mathrm{pH}=1.00-3.00)$ or alkaline medium $(\mathrm{pH}=8.40-10.70)[14,15]$. The choice of acidic rather than alkaline medium for the electrodeposition of CdTe is due to the fact that Te is more soluble and stable in acidic medium. The history of CdTe growth based on electrodeposition using an aqueous electrolyte was first demonstrated by Mathers and Turner in 1928 [13]. A more elaborate work on the electrodeposition of CdTe was carried out by Panicker and Knaster in 1978 [12], and thereafter, many researchers [1,15-19] have electrodeposited CdTe from aqueous solutions. Usually, the electrodeposition of CdTe is carried out using $\mathrm{CdSO}_{4}$ and $\mathrm{TeO}_{2}$, which serve as the $\mathrm{Cd}$ and Te precursors, respectively. The research program continued by BP in the 1980s successfully demonstrated the scaling up of this technology by manufacturing nearly $1.0 \mathrm{~m}^{2}$ in area solar panels with over 10\% conversion efficiency [18]. The successful deposition of CdTe and comprehensive material characterization have also been carried out recently using $\mathrm{CdCl}_{2}[14]$ and $\mathrm{Cd}\left(\mathrm{NO}_{3}\right)_{2}$ precursors [19] for selecting the best cadmium precursor for electroplating. The recent announcement of a $22.1 \%$ efficiency of CdTe solar cells by First Solar company [20] using CdTe grown by vapor transport deposition (VTD) is a giant stride in the PV field showing great potential in CdTe-based thin film solar cells. With all of these attractive properties, CdS/CdTe solar cell efficiency improvement was mostly hindered for decades by a number of challenges; limited know-how on material issues, processing steps and device physics has been the major bottle-necks. Achieving large grains, uniform, dense and pinhole-free thin films with minimum defects and optimum doping concentration have been identified as one of the challenges faced by the PV community.

During the past three decades, CdS/CdTe solar cell research was carried out assuming the CdTe layer in the device as a p-type material. Therefore, all experimental results were interpreted based on a simple p-n junction model. This has led to stagnation of the development of this device for a long period of time. The results presented in this paper aim to demonstrate that both p-type and n-type CdTe layers can be grown easily by changing its composition. Furthermore, this work aims to show that layers may remain n-type after post-growth heat treatments. Therefore, the new work aims to demonstrate that $\mathrm{p}-\mathrm{n}$ junction devices and other complex n-n-n-Schottky barrier-type devices are possible from this material, and the latter seems more efficient in solar energy conversion.

The paper also compares the results obtained from CdTe layers grown by three-electrode (3E) and two-electrode (2E) configurations, in order to gauge the best approach for the minimization 
of impurities. $\mathrm{Ag}^{+}$ions and other group-I ions, such as $\mathrm{Na}^{+}$and $\mathrm{K}^{+}$, are highly poisonous to $\mathrm{CdTe}$ solar cells [21], and the removal of the reference electrode from the electrolyte could be highly beneficial for achieving high performance devices. Reference electrodes usually have a saturated $\mathrm{KCl}$ solution outer jacket in commercially available products with a possibility of leaking $\mathrm{K}^{+}$into the electrolyte. The preliminary studies on the comparison of $3 \mathrm{E}$ and $2 \mathrm{E}$ systems were published recently by Echendu et al. [22]. This paper presents the results of a comprehensive study in order to confirm the conclusions arrived at the initial stages. Removal of the reference electrode from the electrodeposition system introduces several advantages in order to reduce the cost of CdS/CdTe solar cells further. Elimination of a possible impurity source and, hence, achieving high conversion efficiencies, system simplification, cost reduction and the ability to grow improved materials at temperatures higher than the reference electrode limit $\left(70^{\circ} \mathrm{C}\right)$ are some of the advantages.

In this paper, we present the summary of the results for $\mathrm{CdTe}$ thin films grown from aqueous and acidic electrolyte containing $\mathrm{CdSO}_{4}$ and $\mathrm{TeO}_{2}$ using potentiostatic cathodic electrodeposition. After deposition, the films were characterized using a wide range of analytical techniques for structural, morphological, optical and electrical properties. This paper presents the comparison of CdTe layers grown by $3 \mathrm{E}$ and $2 \mathrm{E}$ systems, and their effects on fully-fabricated devices. The paper also provides new insight into the physics of new devices based on CdTe thin films.

\section{Experimental Details}

\subsection{Chemicals and Materials Used}

In this work, cadmium sulfate $\left(\mathrm{CdSO}_{4}\right)$ powder with purity $\geq 99 \%$ was used as the source of $\mathrm{Cd}$ while the source of tellurium $(\mathrm{Te})$ was tellurium oxide $\left(\mathrm{TeO}_{2}\right)$ powder of high purity $(99.999 \%)$. The substrates used were fluorine-doped tin oxide (FTO)-coated glasses with sheet resistance of $13 \Omega$ /square. Dilute sulfuric acid $\left(\mathrm{H}_{2} \mathrm{SO}_{4}\right)$ and ammonium hydroxide $\left(\mathrm{NH}_{4} \mathrm{OH}\right)$ were used for $\mathrm{pH}$ adjustment in solutions. All chemicals and substrates were purchased from Sigma-Aldrich U.K. The solvent used for the electrolyte preparation was de-ionized water. For the 3E system, a saturated calomel electrode (SCE) was used as the reference with a platinum $(\mathrm{Pt})$ anode. The saturated $\mathrm{KCl}$ solution in the outer jacket was replaced by a $\mathrm{Cd}\left(\mathrm{SO}_{4}\right)$ solution in order to avoid $\mathrm{K}$ leakage into the electrolyte. A carbon (C) rod was used as the anode for the 2E system. A clean glass/FTO substrate was used as the cathode for both systems. The source of power was a computerized Gill AC potentiostat, and the heating of the bath was provided by a hot-plate with a magnetic stirrer.

The containers used were Teflon beakers of $1000 \mathrm{~mL}$ for the electrolyte and $2000 \mathrm{~mL}$ Pyrex beakers for the outer jacket. Polytetrafluoroethylene (PTFE) tape was used to hold the glass/FTO substrates to the carbon connecting rod during deposition. The cleaning of the substrates was carried out using organic solvents (methanol and acetone) and de-ionized water.

\subsection{Preparation of Electrolytic Cells}

The electrolytic baths were prepared from aqueous solutions of $1 \mathrm{M} \mathrm{CdSO}_{4}$ and $\mathrm{TeO}_{2}$ solution in $800 \mathrm{~mL}$ of deionized water contained in a $1000 \mathrm{~mL}$ Teflon beaker. The solution containing only low purity $\mathrm{CdSO}_{4}$ was electropurified for $50 \mathrm{~h}$ before adding the high purity $\mathrm{TeO}_{2}$ dilute solution. The main reason for using low-purity $\mathrm{CdSO}_{4}$ is the requirement of a large amount of $\mathrm{CdSO}_{4}$ for this work and the very high cost of the high-purity $\mathrm{CdSO}_{4}$. The $\mathrm{TeO}_{2}$ was separately prepared by dissolving $\mathrm{TeO}_{2}$ powder using dilute sulfuric acid for the addition to the electrolyte. The $\mathrm{pH}$ of the bath was adjusted to $2.00 \pm 0.02$ using $\mathrm{H}_{2} \mathrm{SO}_{4}$ acid or $\mathrm{NH}_{4} \mathrm{OH}$ prior to $\mathrm{CdTe}$ deposition.

The choice of materials to be employed for this experiment is important since the medium of growth is acidic ( $\mathrm{pH}=2.00)$. The acidic electrolyte has been shown to absorb impurities from glass containers and the carbon anode in direct contact. This contamination can be minimized by reducing the contacts between the electrolyte and glass surfaces. [13]. Therefore, the Teflon beakers were used 
as the electrolyte-containing vessels for both $3 \mathrm{E}$ and $2 \mathrm{E}$ systems. This is to minimize impurities, which affect the final device parameters when incorporated into the CdTe layer during growth.

\subsection{Analytical Techniques Used}

A wide range of analytical techniques was used to investigate the electroplated CdTe layers. To study the structural properties, a Philips PW $3710 X^{\prime}$ pert pro diffractometer (Philips Analytical, Almelo, The Netherlands) using the $\mathrm{Cu}-\mathrm{K}_{\alpha}$ excitation wavelength $(\lambda=1.542 \AA)$ was employed, and the scan ranges of $2 \theta\left(20^{\circ}-60^{\circ}\right)$. The morphology of the film surfaces and the grain sizes were observed using the FEG NOVA NANO scanning electron microscope (SEM). The study of the molecular vibration to obtain unique fingerprints of the materials was carried out using a Renishaw Raman microscope (Renishaw Plc, Gloucestershire, UK) with a CCD detector and a $514 \mathrm{~nm}$ argon ion laser. The electrical conduction type of the films was detected using a photoelectrochemical (PEC) cell measurement system using an aqueous electrolyte of $0.1 \mathrm{M} \mathrm{Na}_{2} \mathrm{~S}_{2} \mathrm{O}_{3}$. Optical energy bandgaps were measured using a Cary 50 scan UV-Vis spectrophotometer (Agilent Technologies, Santa Clara, CA, USA). The DC electrical conductivity measurements were carried out using a fully-automated I-V system, including a Keithley 619 electrometer and multimeter (Keithley, Cleveland, OH, USA). Photoluminescence (PL) measurements to observe the defect levels in the bandgap were carried out using a Renishaw inVia Raman microscope (Renishaw, Hoffman Estates, IL, USA) with a CCD detector and a 632-nm He-Ne laser excitation source. Intense pulsed light (IPL) heat treatment was carried out in air using the Sintering 2000 (Xenon Corporation, Wilmington, MA, USA).

\section{Experimental Results}

\subsection{Cyclic Voltammetry}

Figure 1 shows typical voltammograms or current-voltage curves of the electrolytes with $3 \mathrm{E}$ and $2 \mathrm{E}$ electrode systems. Due to the voltage measurement with respect to the reference electrode in the $3 \mathrm{E}$ and the carbon anode in the $2 \mathrm{E}$ system, the magnitudes of the cathodic voltages are different in the graphs. Otherwise, the main features are similar in both cases.

The mechanism for the deposition of CdTe on the cathode from acidic aqueous electrolyte as proposed by Panicker et al. [12] is given below using Equations (1) and (2). The first process, which is a diffusion control, is the reduction of $\mathrm{HTeO}_{2}{ }^{+}$to $\mathrm{Te}$, which reacts with $\mathrm{Cd}^{2+}$ to form $\mathrm{CdTe}$ on the cathode. The formation of CdTe thin films on the cathode is highly influenced by the diffusion process. The overall equations for the formation of $\mathrm{CdTe}$ on the cathode are given below:

$$
\begin{aligned}
\mathrm{HTeO}_{2}{ }^{+}+3 \mathrm{H}^{+}+4 \mathrm{e}^{-} & \rightarrow \mathrm{Te}+2 \mathrm{H}_{2} \mathrm{O} \\
\mathrm{Cd}^{2+}+\mathrm{Te}+2 \mathrm{e} & \rightarrow \mathrm{CdTe}
\end{aligned}
$$

Since the redox potential of $\mathrm{Te}$ is $+0.593 \mathrm{~V}$ with respect to the standard $\mathrm{H}_{2}$ electrode, this element is easier to deposit on the cathode first. In the $3 \mathrm{E}$ system, Te deposition starts around $200 \mathrm{mV}$, and then, at higher cathodic voltages of around $550 \mathrm{mV}, \mathrm{Cd}$ starts to deposit (the redox potential of $\mathrm{Cd}$ is $-0.403 \mathrm{~V}$ with respect to the standard $\mathrm{H}_{2}$ electrode). As a result, when the cathodic potential is gradually increased, the sequence of deposition is: Te layer first, Te-rich CdTe second, stoichiometric CdTe third and, finally, Cd-rich CdTe layers. This transition takes place gradually, and at a certain voltage, the stoichiometric CdTe layer is formed. This voltage is labelled as the perfect potential of stoichiometry (PPS) in this paper. This is the voltage we expect to find for growing device-quality $\mathrm{CdTe}$ layers. In the reverse scan, when the cathodic voltage is gradually reduced, the material starts to dissolve in the solution. The dissolution order will be elemental $\mathrm{Cd}$ first, $\mathrm{Cd}$ from $\mathrm{CdTe}$ second and, finally, Te from the cathode surface. This dissolution process creates a current flow in the negative direction. The large peak in the negative current represents the dissolution of both $\mathrm{Cd}$ and $\mathrm{Te}$ from the cathode surface. 


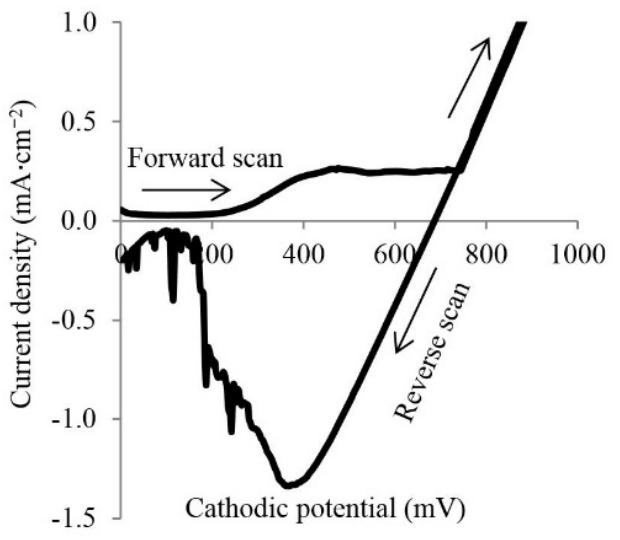

(a)

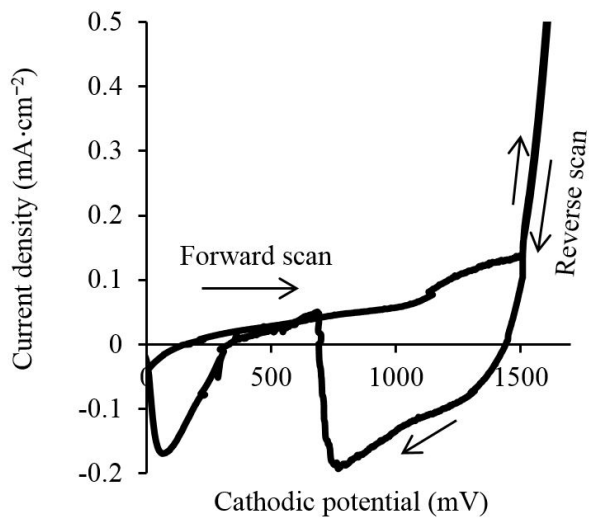

(b)

Figure 1. Cyclic voltammograms of aqueous solutions consisting of $1 \mathrm{M} \mathrm{CdSO}_{4}$ and a low level of $\mathrm{TeO}_{2}$ with glass /FTO cathode in (a) three-electrode (3E) and (b) two-electrode (2E) systems. The reference electrode used for the $3 \mathrm{E}$ system is a standard calomel electrode. The growth temperature was $70{ }^{\circ} \mathrm{C}$ and $85{ }^{\circ} \mathrm{C}$ for the $3 \mathrm{E}$ and $2 \mathrm{E}$ systems, respectively. The $\mathrm{pH}$ of both electrolytes was set to $2.00 \pm 0.02$ at the beginning of the experiment at room temperature.

The main features of the voltammogram for the 2E system are the same, but the absolute values of the cathodic voltages are different. It should be noted that these deposition voltages are very different from the redox potentials given above. The reason is that the redox potentials are given w.r.t. the standard $\mathrm{H}_{2}$ electrode, and the measured values in these experiments are w.r.t. the carbon anode, for $2 \mathrm{E}$, and the standard calomel electrode for the $3 \mathrm{E}$ system. Te deposition starts around $250 \mathrm{mV}$, and Cd deposition takes place around $1000 \mathrm{mV}$. In the reverse direction, $\mathrm{Cd}$ dissolution and Te dissolution are shown in two separate current peaks. This peak separation can be due to different experimental conditions, such as scan rate, different temperature and the stirring rates.

\subsection{X-ray Diffraction}

Careful observation of the voltammogram helps with estimating suitable cathodic voltages for growing stoichiometric CdTe. By growing layers at fixed voltages in this estimated region and observations using XRD, PEC and optical absorption methods, this estimated voltage range can be reduced to a very narrow range. In this study, these voltages were changed by 2 and $1 \mathrm{mV}$ steps for the $3 \mathrm{E}$ and 2E systems, respectively, in order to pin-point the perfect potential of stoichiometry (PPS).

Figure 2 shows the XRD spectra measured for samples grown in the vicinity of PPS from both the $3 \mathrm{E}$ and 2E systems. Figure 2a shows the variation of XRD observed for CdTe grown by the 3E system. Every effort was taken to grow approximately equal thicknesses, and the variation of the intensity of the most intense (111) peak was closely monitored. It was found that the highest intensity was observed when the layers were grown at $834 \mathrm{mV}$. When heat treated in the presence of $\mathrm{CdCl}_{2}$ (Figure 2c), the intensity variation remained the same, confirming that the highest crystallinity shifted to $830 \mathrm{mV}$ w.r.t. the calomel reference and Pt anode. Therefore, the PPS value for the 3E system is confirmed as $830 \mathrm{mV}$ with respect to SCE under the experimental condition used in this work. This voltage was taken as the PPS, since $\mathrm{CdCl}_{2}$ treatment is used prior to the fabrication of CdS/CdTe solar cells.

Figure $2 b$,d shows similar results for CdTe grown by the 2E system. XRD features remain the same, and PPS for this experimental system can be determined as $1576 \mathrm{mV}$ with respect to the carbon anode. All other XRD features are very similar, but the growth rate is usually faster in the 2E system, when compared to the $3 \mathrm{E}$ system. This can be taken as an advantage in the manufacturing process, reducing growth time. In the case of heat-treated samples in the presence of $\mathrm{CdCl}_{2}$, the (220) and (311) peaks start to appear. This shows that the grains are losing their preferential orientation along (111). 


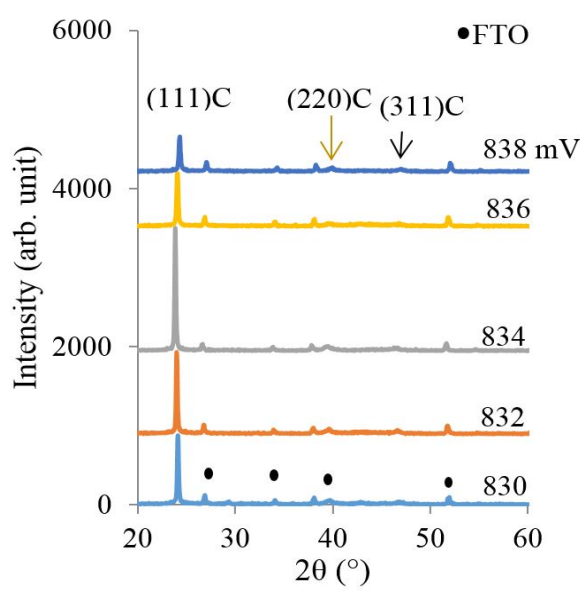

(a) AD-CdTe from 3E

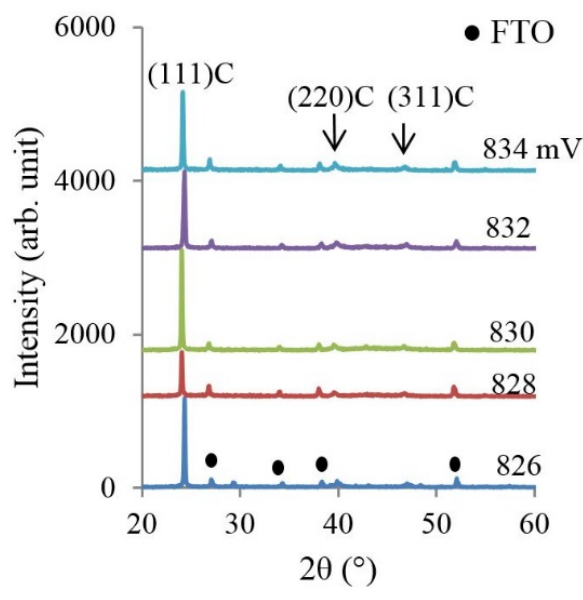

(c) $\mathrm{CdCl}_{2}$-treated CdTe from $3 \mathrm{E}$

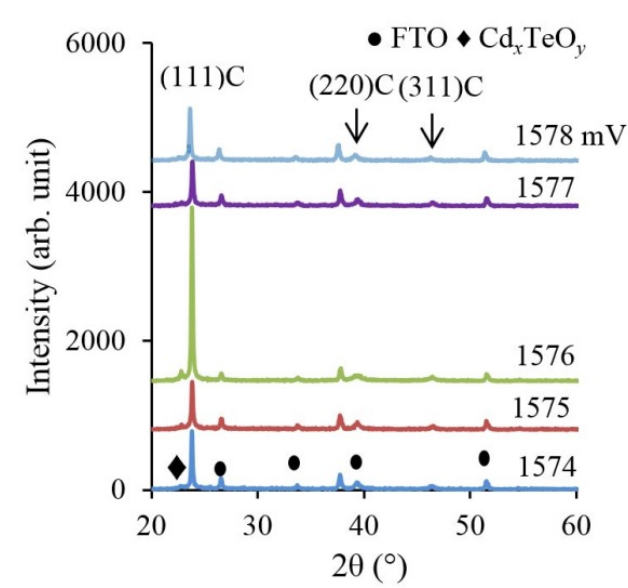

(b) AD-CdTe from $2 \mathrm{E}$

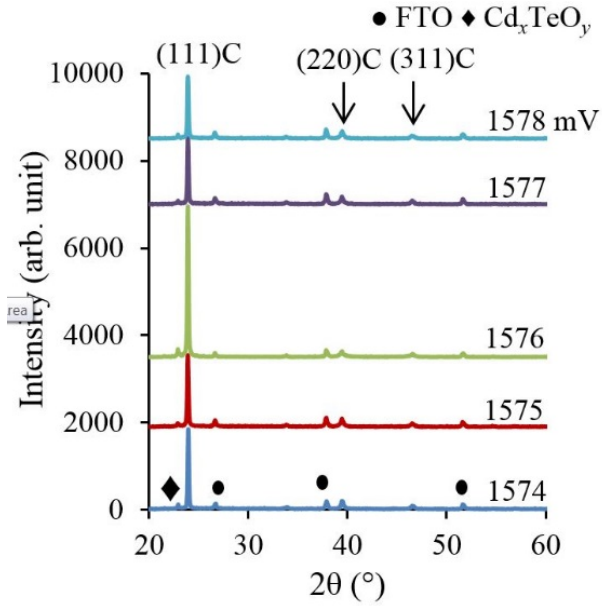

(d) $\mathrm{CdCl}_{2}$-treated CdTe from $2 \mathrm{E}$

Figure 2. XRD patterns for as-deposited (AD) CdTe films deposited at different growth voltages using the (a) $3 \mathrm{E}$ and (b) $2 \mathrm{E}$ systems. (c,d) $\mathrm{XRD}$ patterns for $\mathrm{CdCl}_{2}$-treated layers. All heat treatments were carried out at $400{ }^{\circ} \mathrm{C}$ for $15 \mathrm{~min}$ in air in the presence of $\mathrm{CdCl}_{2}$.

In both cases, the (111) peak of as-deposited CdTe layers was used to estimate the crystallite sizes. The use of Scherrer's equation yields $(20-65 \mathrm{~nm})$ for the crystallite size for both material layers.

\subsection{Scanning Electron Microscopy}

Scanning electron microscopy (SEM) studies were carried out in order to investigate the surface morphology of electroplated CdTe layers using both the 3E and 2E systems. Typical results are shown in Figure 3 for both as-deposited and $\mathrm{CdCl}_{2}$-treated layers. The as-deposited layers of 3E (Figure 3a) and $2 \mathrm{E}$ (Figure $3 \mathrm{~b}$ ) are covered with large clusters or agglomerations consisting of nano-crystallites. The clusters have varying sizes up to the sub-micron level for the largest ones. The small grains are crystalline CdTe, and their size varies from $(20-65 \mathrm{~nm})$ as determined by XRD measurements and Scherrer's equation. There is no noticeable difference in the morphology and crystallite sizes for 3Eand 2E-grown CdTe layers. Only the cluster size is larger in the layers grown by the 2E system.

Heat treatment at $450{ }^{\circ} \mathrm{C}$ for $20 \mathrm{~min}$ in air in the presence of $\mathrm{CdCl}_{2}$ (Figure 3c,d) shows a dramatic change. Nano-crystallites within clusters have merged together to form large crystals, and the clusters become large grains of CdTe. This is thermodynamically expected since the surface to volume ratio is large for nano-crystallites. Grain sizes vary in the few microns size, and these layers show similarity in structure to CdTe grown by high temperature techniques, such close-spaced sublimation (CSS). 
Prolong heating at temperatures $450{ }^{\circ} \mathrm{C}$ makes these grains larger due to Oswald ripening, but detrimental for device performance. This is due to the columnar growth producing larger grains exposing wider gaps between grains. In addition, the material losses due to sublimation have also been observed. Both of these processes increase pinhole or gap formation and therefore are detrimental for final device performance.

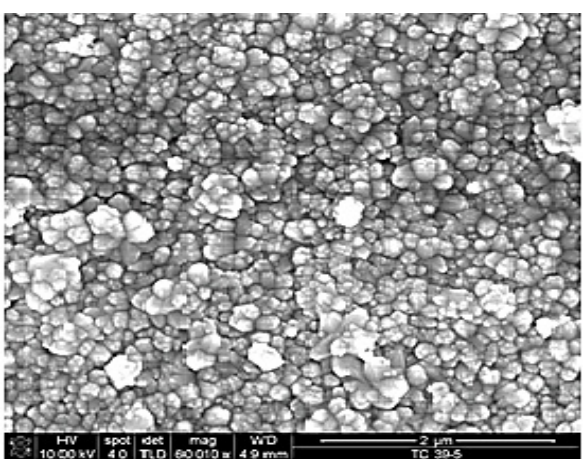

(a) As-deposited CdTe (3E)

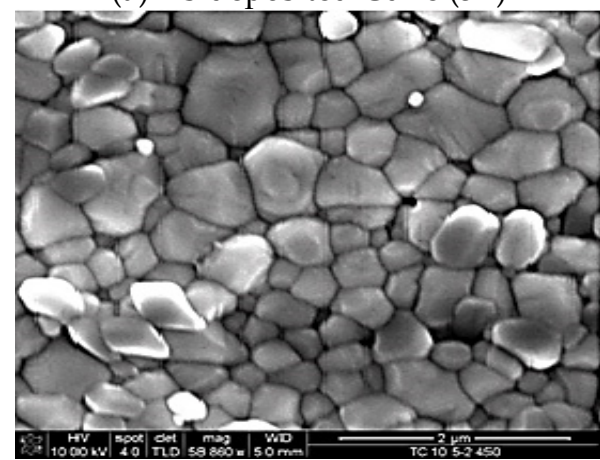

(c) $\mathrm{CdCl}_{2}$-treated $\mathrm{CdTe}(3 \mathrm{E})$

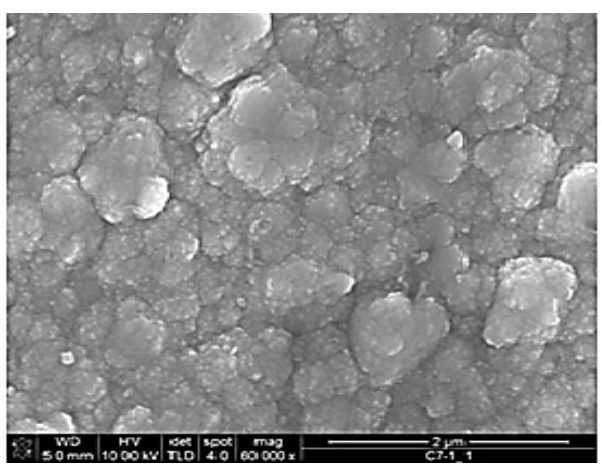

(b) As-deposited CdTe (2E)

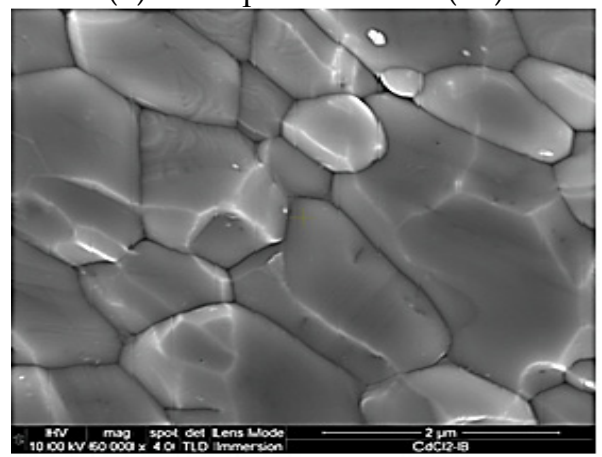

(d) $\mathrm{CdCl}_{2}$-treated CdTe (2E)

Figure 3. Typical SEM images for as-deposited and $\mathrm{CdCl}_{2}$-treated $\mathrm{CdTe}$ layers grown by the $3 \mathrm{E}$ system $(\mathbf{a}, \mathbf{c})$ and the $2 \mathrm{E}$ system $(\mathbf{b}, \mathbf{d}) . \mathrm{CdCl}_{2}$ treatment was carried out in a conventional furnace at $450{ }^{\circ} \mathrm{C}$ for $20 \mathrm{~min}$ in air, in the presence of $\mathrm{CdCl}_{2}$.

The heat treatment is crucial in device performance, and the PV solar cell developers are moving towards roll-to-roll production methods. Therefore, intense pulse light (IPL) annealing was also used to study the morphology changes during heat treatment. IPL is a rapid thermal annealing method applicable to materials grown on flexible substrates, and the CdTe layer can be heat treated from the top surface using pulses of white light. Heat energy released to the material layer can be controlled by the energy of a pulse and the number of pulses used to heat the layer. Full details of this technique are given in [23], and here, the main morphology changes of the surfaces are presented and discussed.

Figure 4a shows another SEM image of a CdTe layer grown by the 2E system. These surfaces are very similar to the ones shown in Figure 3a,b. Small crystallites are clustered together to form large agglomerations. Figure $4 \mathrm{~b}, \mathrm{c}, \mathrm{d}$ shows the surface morphology after IPL treatments with energies of $1730 \mathrm{~J} \cdot \mathrm{cm}^{-2}\left(100\right.$ pulses $\left.\times 17.3 \mathrm{~J} \cdot \mathrm{cm}^{-2}\right), 2160 \mathrm{~J} \cdot \mathrm{cm}^{-2}\left(100\right.$ pulses $\left.\times 21.6 \mathrm{~J} \cdot \mathrm{cm}^{-2}\right)$ and $2588 \mathrm{~J} \cdot \mathrm{cm}^{-2}$ $\left(100\right.$ pulses $\left.\times 25.9 \mathrm{~J} \cdot \mathrm{cm}^{-2}\right)$, respectively.

From these SEM images, it is clear that the agglomerations become large crystalline grains, after mainly the grain boundary areas melting and subsequently freezing during cooling. Figure $4 \mathrm{~d}$ clearly shows the large CdTe grains formed across the thin layer. Cross-section SEM images show that those grains have a columnar nature, spreading from the bottom to the top of the thin films. It also shows the melted grain boundaries frozen after heat treatment. As shown by the phase diagram of CdTe [7], the melting point of grain boundary materials with impurities, such as $\mathrm{O}, \mathrm{Cl}$ and excess $\mathrm{Cd}$ from $\mathrm{CdCl}_{2}$, are much lower $\left(350-450^{\circ} \mathrm{C}\right)$ than the melting point of pure CdTe grains $\left(1093^{\circ} \mathrm{C}\right)$. 
Therefore during heat treatment, grain boundaries become a liquid, allowing CdTe grains to flow, coalesce and grow into large grains.

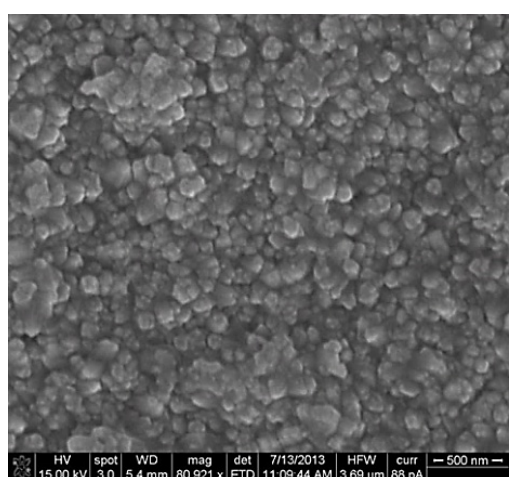

(a) As-deposited CdTe (2E)

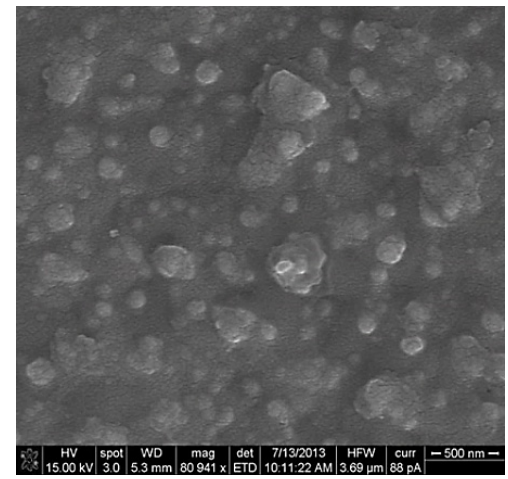

(c) layer (a), IPL treated with $2160 \mathrm{~J} \cdot \mathrm{cm}^{-2}$

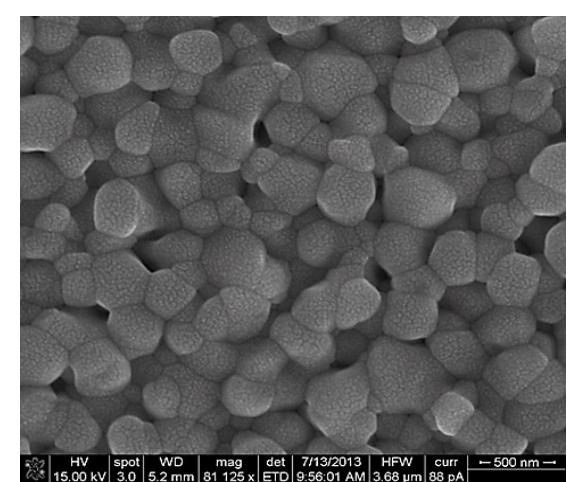

(b) layer (a), IPL treated with $1730 \mathrm{~J} \cdot \mathrm{cm}^{-2}$

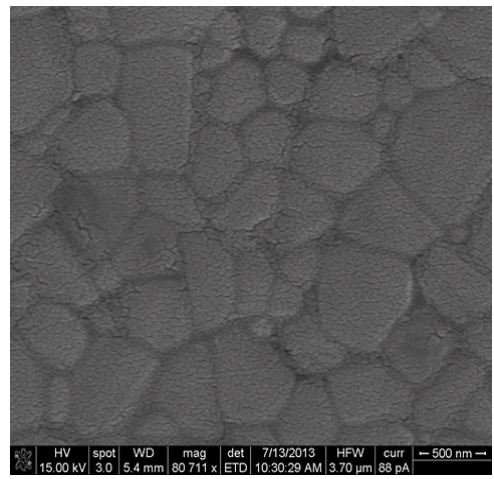

(d) layer (a), IPL treated with $2588 \mathrm{~J} \cdot \mathrm{cm}^{-2}$

Figure 4. A typical SEM image of the as-deposited CdTe layer from the 2E system and changes of morphology as the energy input is increased using intense pulse light (IPL) treatment.

\subsection{Photoelectrochemical Cell Measurements}

In order to use a material in any electronic device and interpret the experimental results, its electrical conductivity type must be accurately known. The most accurate method to find this is the conventional Hall effect measurements, but these studies cannot be performed on glass/FTO/CdTe layers due to the underlying conducting layer of FTO. Electrons find the lowest resistive path, and therefore, measurements are not at all reliable. For this reason, the photoelectrochemical (PEC) cell measurements have been used to find the electrical conduction type of these layers.

For these measurements, glass/FTO/CdTe was immersed in any suitable electrolyte (aqueous solution of $\mathrm{Na}_{2} \mathrm{~S}_{2} \mathrm{O}_{3}$ for example) in order to form a solid/liquid junction at the $\mathrm{CdTe} /$ electrolyte interface. This is equivalent to a weak Schottky diode, and its open circuit voltage is measured by measuring its voltage with respect to a counter electrode (graphite rod) immersed in the same electrolyte. The difference between the voltages measured under dark and illuminated conditions provides the PEC signal. After calibrating the system with a known material, the sign of the open circuit voltage or the PEC signal determines the electrical conductivity type of the CdTe layer. The magnitude of the PEC signal indicates the strength of the depletion region formed at the solid/liquid junction and, hence, an indirect and qualitative idea of the doping level of CdTe layer. Both insulating and metallic layers provide a zero PEC signal due to the non-formation of a healthy depletion region. In our calibrated system, the positive PEC signal indicates a p-type semiconductor, and a negative signal shows an n-type semiconductor.

Figure $5 \mathrm{a}, \mathrm{b}$ shows the PEC signals observed for as-deposited and $\mathrm{CdCl}_{2}$-treated $\mathrm{CdTe}$ layers grown from both the $3 \mathrm{E}$ and $2 \mathrm{E}$ systems, as a function of growth voltage. Both CdTe materials grown 
using the $3 \mathrm{E}$ and $2 \mathrm{E}$ systems show a similar behavior. At low cathodic voltages, Te-rich, p-type $\mathrm{CdTe}$ layers are grown, while at larger cathodic voltages, Cd-rich, n-type CdTe layers are grown. In between these two regions, there exists an inversion voltage $\left(V_{\mathrm{i}}\right)$ or perfect potential of stoichiometry (PPS), which produces stoichiometric CdTe with the highest crystallinity due to the existence of only one phase. Crystallinity of the layers reduces when grown away from $V_{\mathrm{i}}$ or PPS due to the presence of two phases within the layer. The absolute value of $V_{\mathrm{i}}$ varies depending on factors, such Te concentration, stirring rate and $\mathrm{pH}$ value.

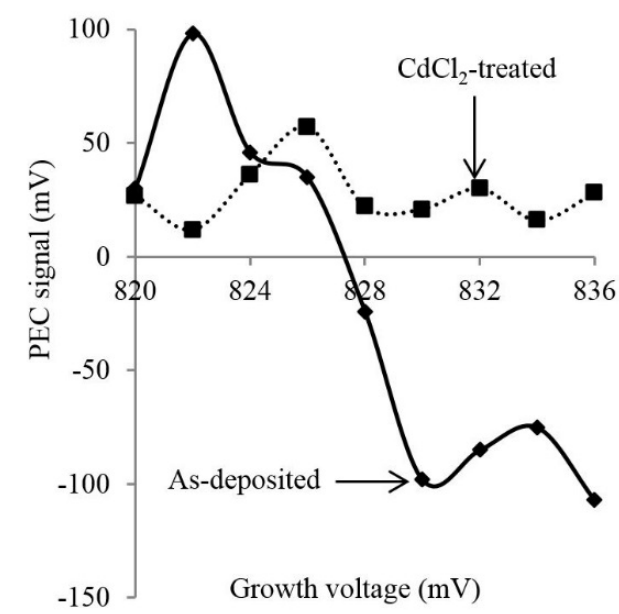

(a) (PEC Signal) for CdTe (3E)

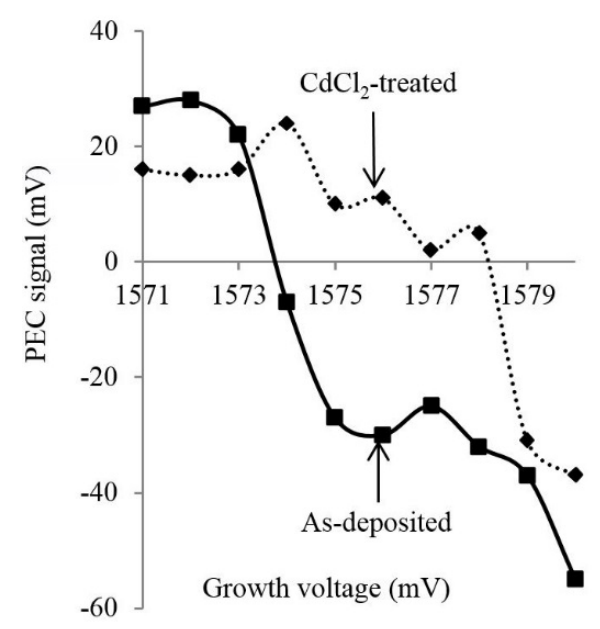

(b) (PEC Signal) for CdTe (2E)

Figure 5. Photoelectrochemical (PEC) cell measurements for as-grown and $\mathrm{CdCl}_{2}$-treated $\mathrm{CdTe}$ thin films deposited using (a) 3E and (b) 2E systems at different growth voltages. Samples were heat-treated at $400{ }^{\circ} \mathrm{C}$ for $15 \mathrm{~min}$ in air in the presence of $\mathrm{CdCl}_{2}$.

Upon $\mathrm{CdCl}_{2}$ treatment, both materials maintain a similar behavior. The p-type nature reduces and moves towards the n-type property, and the n-type nature reduces and moves towards the p-type property. It should be noted that this is due to the movement of the Fermi level within the bandgap, and complete type conversion may not occur. This shows the direction of movement of the Fermi level (FL) in the bandgap depending on the initial condition of the layer, doping effects and annealing out defects during the heat treatment. These measurements indicate only the electrical conductivity type of the top layers of CdTe materials, since the depletion region formed at the solid/liquid junction is limited only to the surface region.

\subsection{Raman Studies}

Raman scattering studies were carried out as a non-destructive and quick quality control method. This could be useful in a production line to check the quality of materials grown before processing devices. In our previous Raman studies [14,24,25], the peak arising from both CdTe and elemental Te was observed. The $\mathrm{X}$ - and $\gamma$-ray detectors research community has carried out comprehensive studies on Te-precipitation during CdTe growth [26,27]. In agreement with the reports, we also observe Raman peaks arising from elemental Te in electrodeposited CdTe layers.

Figure 6 shows typical Raman spectra of CdTe layers grown near the PPS, using both 3E $\left(V_{\mathrm{g}}=828 \mathrm{mV}\right)$ and $2 \mathrm{E}\left(V_{\mathrm{g}}=1360 \mathrm{mV}\right)$ systems. In addition to the peak arising from CdTe at $161 \mathrm{~cm}^{-1}$, peaks at 121 and $141 \mathrm{~cm}^{-1}$ can be identified as Te peaks. These elemental Te could appear as precipitates within the layer or Te thin film on the surface. As observed from PL (Section 3.7) and the overall devices' work (Section 3.9), excess Te in the CdTe layers deteriorates its electronic properties.

$\mathrm{CdCl}_{2}$ treatment, however, tends to reduce the elemental Te in the layers by reacting with $\mathrm{Cd}$ from $\mathrm{CdCl}_{2}$ and forming $\mathrm{CdTe}$, in addition to other benefits, such as re-crystallization, reduction of 
grain boundaries, defects and doping. As shown in Figure 6, both CdTe layers from the 3E and 2E systems show a similar reduction of elemental Te from the electroplated CdTe layers.

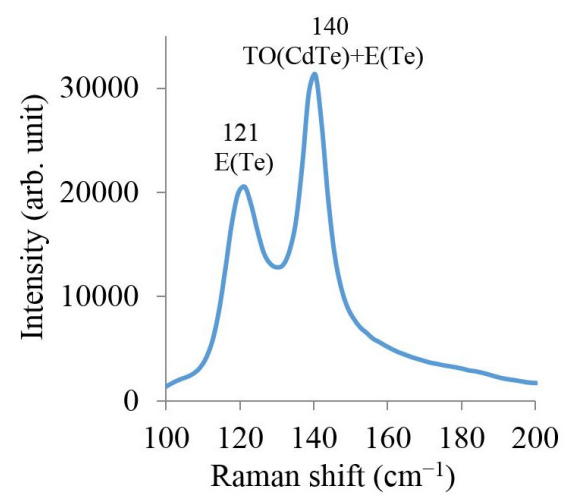

(a) As-deposited CdTe (3E)

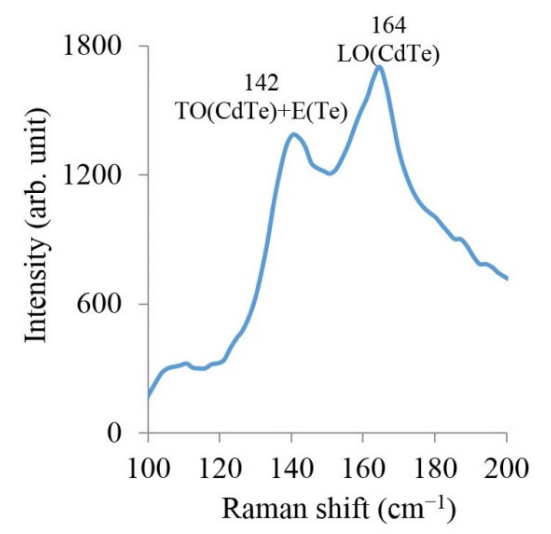

(c) $\mathrm{CdCl}_{2}$-treated CdTe (3E)

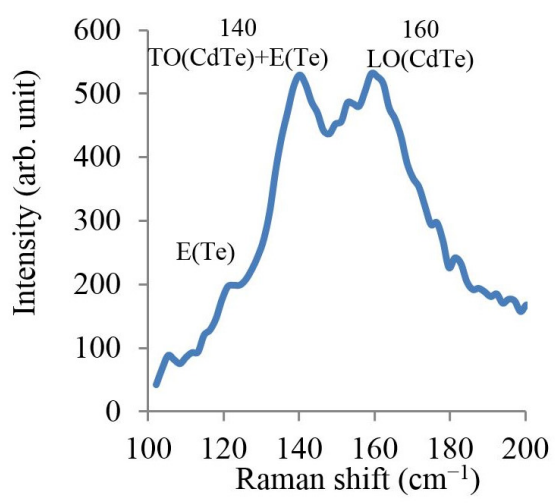

(b) As-deposited CdTe (2E)

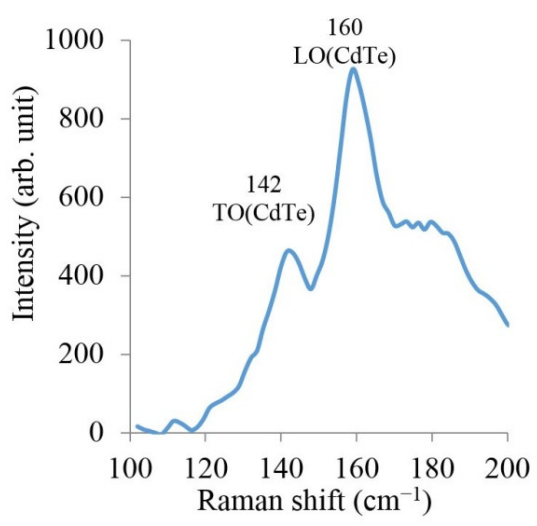

(d) $\mathrm{CdCl}_{2}$-treated CdTe (2E)

Figure 6. Plot of the Raman spectra of CdTe thin films for as-deposited and $\mathrm{CdCl}_{2}$-treated layers. The samples were grown using $(\mathbf{a}, \mathbf{c}) 3 \mathrm{E}$ and $(\mathbf{b}, \mathbf{d}) 2 \mathrm{E}$, respectively. The surfaces were thoroughly washed with deionized water after $\mathrm{CdCl}_{2}$ treatment.

\subsection{Optical Absorption}

Optical absorption studies were carried out in order to study the absorption edge and estimate the optical energy gap of the material. This analysis usually plots $\left(\alpha h v^{2}\right)$ versus photon energy $(h v)$ or Tauc plots to determine energy gap values. In this research program, we have found that plots of the square of optical absorption $\left(A^{2}\right)$ versus photon energy $(h v)$ also produce very similar results, and therefore, Figure 7 shows the plots obtained for electroplated CdTe layers using the 3E and 2E systems.

It is a notable feature of the curves that when the material layers are grown at PPS, the optical absorption edge is sharp and produces accurate $E_{\mathrm{g}}$ values. Stoichiometric CdTe layers grown using both the $3 \mathrm{E}$ and $2 \mathrm{E}$ systems produce a bandgap of $1.48 \mathrm{eV}$ very close to that of the bulk CdTe material. As the growth voltage deviates from the PPS, the slope of the absorption edge weakens and produces $E_{\mathrm{g}}$ values away from the bulk energy gap. The presence of several phases in the layer tends to produce smaller crystallites and, hence, produce slightly larger $E_{\mathrm{g}}$ values. Te precipitates, Te-rich CdTe and stoichiometric CdTe, when grown below PPS, are possible, and the layer consists of smaller grains and more pinholes. More pinholes means the passage of all wavelengths and, therefore, equivalent to lager bandgaps. The addition of more metallic cadmium when grown above PPS tends to reduce the bandgap due to the metallic property of $\mathrm{Cd}$. 


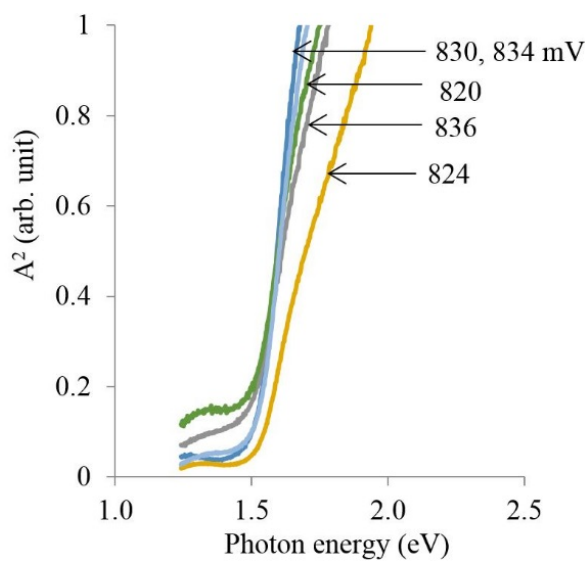

(a) As-deposited

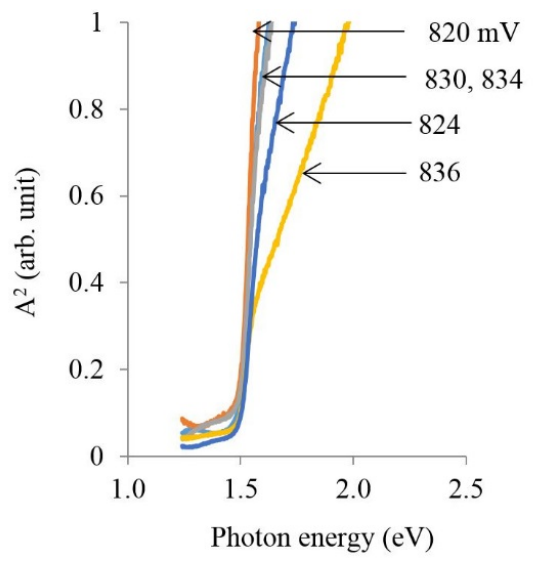

(c) $\mathrm{CdCl}_{2}$-treated $\mathrm{CdTe}(3 \mathrm{E})$

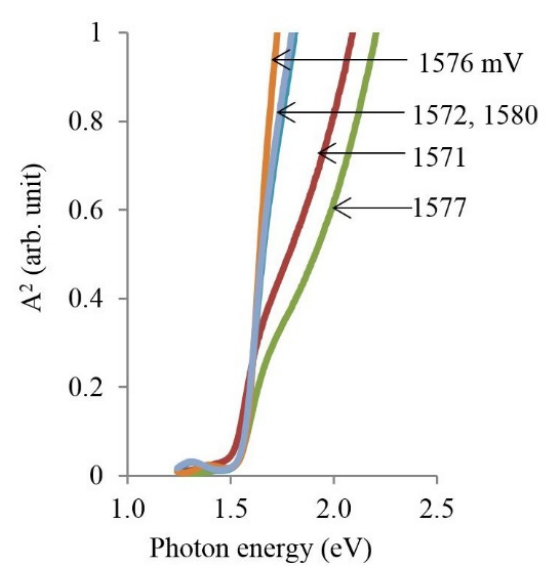

(b) As-deposited CdTe (2E)

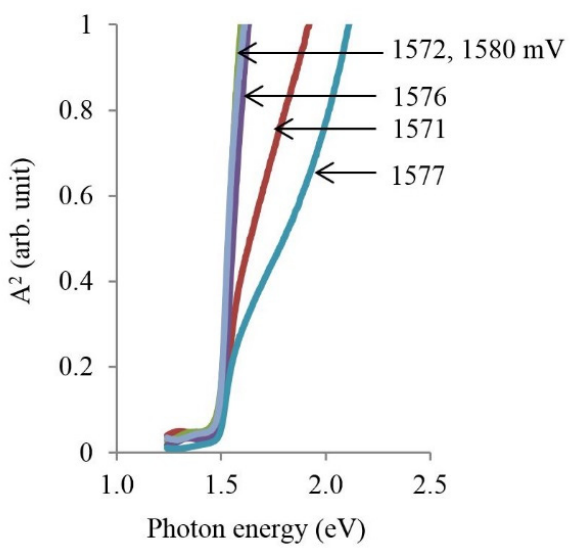

(d) $\mathrm{CdCl}_{2}$-treated CdTe (2E)

Figure 7. Optical absorption edges for as-deposited and $\mathrm{CdCl}_{2}$-treated $\mathrm{CdTe}$ layers grown using the $3 \mathrm{E}(\mathbf{a}, \mathbf{c})$ and $2 \mathrm{E}(\mathbf{b}, \mathbf{d})$ systems at different growth potentials. The films were heat-treated at $400{ }^{\circ} \mathrm{C}$ for $15 \mathrm{~min}$ in air.

\subsection{Photoluminescence Studies}

Photoluminescence studies were carried out on both as-deposited and $\mathrm{CdCl}_{2}$-treated $\mathrm{CdTe}$ layers obtained from the $3 \mathrm{E}$ and 2E electrodeposition systems. The aim was to observe the defect structure in the materials' bandgap. The PL system used is capable of detecting materials' defects between $0.55 \mathrm{eV}$ below the conduction band and the top of the valence band. Full details of the experimental setup and other PL work are published elsewhere [28].

Figure 8 shows the experimentally-observed PL spectra for these CdTe layers for direct comparison. PL spectra from ED-CdTe layers grown from both the 3E and 2E systems show similar defect structures. Defect fingerprints consist of four main defect distributions $\left(T_{1}-T_{4}\right)$ and the near band emission peak, labelled as $E_{\mathrm{g}}$. The PL peaks are labeled as $T_{1}-T_{4}$, only to aid the discussion, but those broad peaks could include several peaks arising from closely-situated defects. The summary of the emission levels is shown in Table 1 with approximate energy distributions.

There are some important features to note in these PL spectra. The mid-gap peak labelled as $T_{2}$ is the most detrimental "killer center" in CdTe and related to Te richness in CdTe [29,30]. Therefore, these defects' distribution must be related to tellurium antisites $\left(\mathrm{Te}_{\mathrm{Cd}}\right)$, tellurium interstitials $\left(\mathrm{Te}_{\mathrm{i}}\right)$ and cadmium vacancies $\left(V_{\mathrm{Cd}}\right)$. This defects' distribution is very broad and spread over $0.30 \mathrm{eV}$, contributing to detrimental and effective recombination of photo-generated charge carriers. In the case of CdTe grown using the $2 \mathrm{E}$ system, these defects' reduction is more apparent after $\mathrm{CdCl}_{2}$ treatment. Sharpening of the $E_{\mathrm{g}}$ peak is also clear for these layers. Therefore, based on the PL spectra, 
both materials are comparable; if not, the materials arising from the $2 \mathrm{E}$ systems are slightly superior. In order to produce high efficiency devices, these mid-gap "killer centers" $\left(T_{2}\right)$ should be completely removed or at least minimized to reduce the recombination of photo-generated charge carriers.

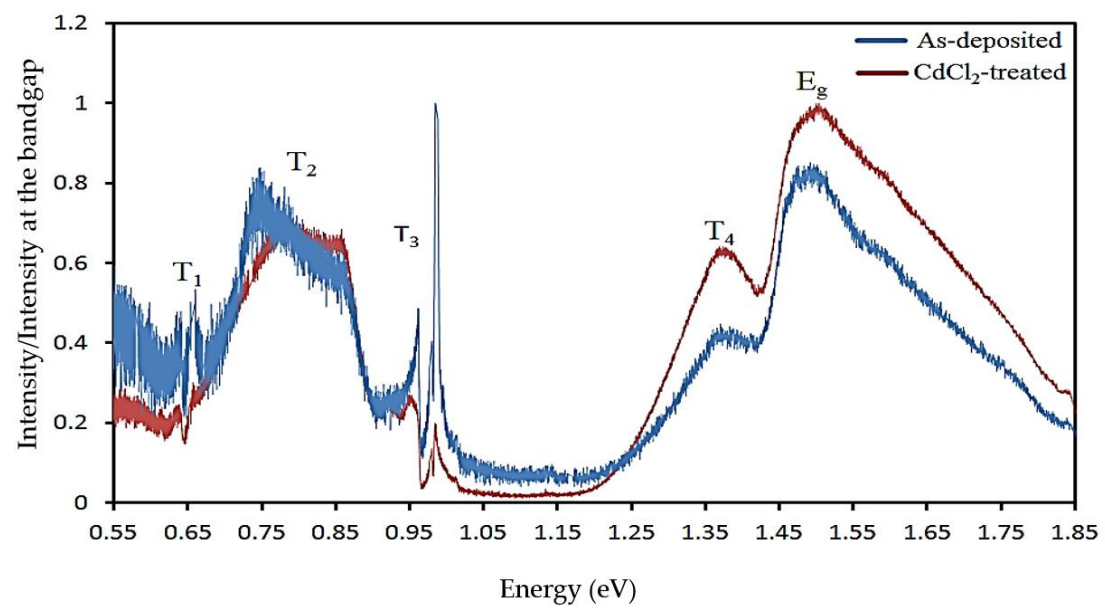

(a) CdTe-PL for $3 \mathrm{E}$

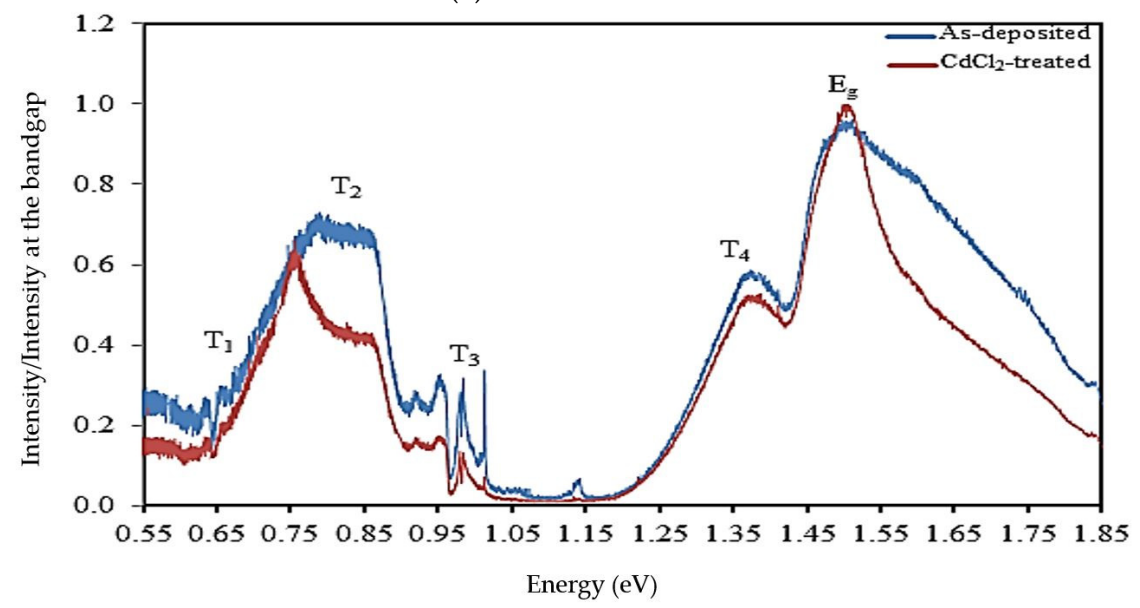

(b) CdTe-PL for 2E

Figure 8. Photoluminescence spectra obtained for as-deposited and $\mathrm{CdCl}_{2}$-treated $\mathrm{CdTe}$ layers grown from (a) $3 \mathrm{E}$ and (b) $2 \mathrm{E}$ systems.

Table 1. Summary of electron traps observed at $80 \mathrm{~K}$ for CdTe layers electroplated using the $3 \mathrm{E}$ and 2 E systems.

\begin{tabular}{cccccc}
\hline \multirow{2}{*}{ CdTe Layers } & \multicolumn{5}{c}{ Energy Position Below the Conduction Band Minimum (eV) } \\
\cline { 2 - 6 } & $\boldsymbol{T}_{\mathbf{1}} \pm \mathbf{0 . 0 2}$ & $\boldsymbol{T}_{\mathbf{2}} \pm \mathbf{0 . 1 5}$ & $\boldsymbol{T}_{\mathbf{3}} \pm \mathbf{0 . 0 3}$ & $\mathbf{T}_{\mathbf{4}} \pm \mathbf{0 . 0 8}$ & $\boldsymbol{E}_{\mathbf{g}}$ Peak \\
\hline As-deposited (3E) & 0.66 & 0.75 & 0.97 & 1.37 & 1.50 \\
CdCl $_{2}$-treated (3E) & - & 0.77 & 0.97 & 1.37 & 1.50 \\
As-deposited (2E) & 0.66 & 0.79 & 0.96 & 1.37 & 1.51 \\
CdCl $_{2}$-treated (2E) & - & 0.75 & 0.96 & 1.37 & 1.50 \\
\hline
\end{tabular}

In $[29,30]$, it has been clearly demonstrated that the CdTe layers can be produced with Te-rich or $\mathrm{Cd}$-rich conditions. This work also showed that the largest Schottky barriers are produced on Cd-rich surfaces rather than Te-rich surfaces. Cd-rich CdTe removes mid-gap killer centers and pins the Fermi level close to the valence band maximum, producing excellent diodes. Therefore, high efficiency solar cells can be produced using a Cd-rich CdTe layer, as shown in Figure 9b. 


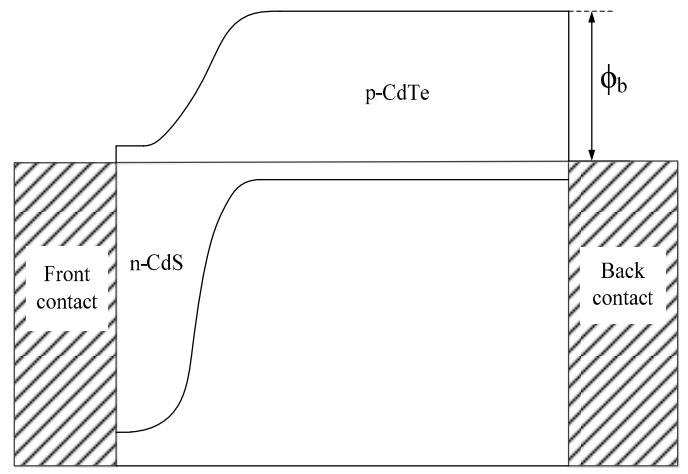

(a)

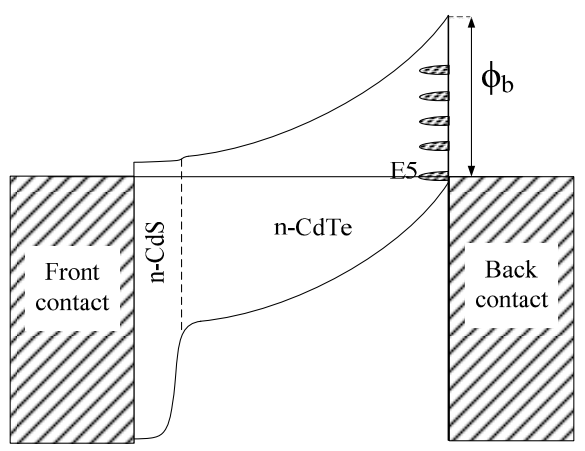

(b)

Figure 9. Possible device configurations when CdTe layers are used as (a) p-type and (b) n-type in electrical conduction.

\subsection{Ultraviolet Photoelectron Spectroscopy}

In the development of thin film solar cells based on CdTe, the usual superstrate device structure used is glass/FTO/CdS/CdTe/back electrical contact. Since CdTe exists both in n-type and p-type electrical conductivity, two PV devices are possible [31], as shown in Figure 9.

The above structure forms a simple p-n junction when the CdTe layer is p-type and forms an n-n heterojunction connected in parallel with a large Schottky barrier (SB) at the back metal contact $(n-n+S B)$ when the CdTe layer is n-type. In both cases, the Fermi level (FL) should align very close to the valence band maximum, in order to produce high efficiency solar cells. However, strong FL pinning occurs at $\mathrm{CdTe} /$ metal interfaces as reported in [3]. Therefore, the knowledge on the positions of the FL at the CdTe back surface is useful in this device development program. In order to gather any useful information, ultraviolet photoelectron spectroscopy (UPS) studies were carried out. The detailed results on UPS and the observed results are published elsewhere [32].

After a comprehensive UPS study, it was found that the results need to be carefully analyzed depending on the surface preparations. UPS is a surface-sensitive technique (probing depth is one or two monolayers), and therefore, the results can depend on various factors, such as the length of exposure to the atmosphere. However, UPS results also provide valuable information on the interactions at the $\mathrm{CdTe} / \mathrm{Au}$ electrical contacts. It measures the work function of the Au layer deposited on CdTe and that of the CdTe surface. Typical values measured are shown in Table 2.

Table 2. Summary of the work function measured for $\mathrm{Au}$ and CdTe surfaces using ultraviolet photoelectron spectroscopy (UPS).

\begin{tabular}{cccc}
\hline Growth System & Material Used & Work Function of Au (eV) & Work Function of CdTe (eV) \\
\hline \multirow{2}{*}{ CdTe from 3E } & $\mathrm{CdTe}\left(\mathrm{CdCl}_{2}\right)$ & 4.31 & 3.89 \\
& $\mathrm{CdTe}\left(\mathrm{CdSO}_{4}\right)$ & 4.42 & 4.00 \\
\hline \multirow{2}{*}{ CdTe from 2E } & $\mathrm{CdTe}(\mathrm{CdSO} 4)$ & 4.39 & 4.35 \\
& $\mathrm{CdTe}(\mathrm{Cd}(\mathrm{NO}) 2)$ & 4.60 & 3.61 \\
\hline
\end{tabular}

The reported work functions for $\mathrm{Au}$ and Te are 5.10 [33] and $4.73 \mathrm{eV}$ [34], respectively. It is clear that the average work function measured for Au contacts deposited on the CdTe layer is $4.40 \mathrm{eV}$ and less than $5.10 \mathrm{eV}$ (see the last column of Table 2). This confirms our previous conclusions based on soft-XPS results carried out at the synchrotron radiation laboratory in Daresbury. As Au is deposited on CdTe, a strong interaction takes place by Au alloying with $\mathrm{Cd}$ and releasing Te to the surface of the $\mathrm{Au}$ layer [3,35]. As a result, the Au layer is not pure $\mathrm{Au}$ and consists of floating $\mathrm{Te}$ or $\mathrm{Au}_{\mathrm{x}} \mathrm{Te}_{\mathrm{y}}$ alloy. Exposure to the atmosphere could oxidize some of the Te into $\mathrm{Te}_{x} \mathrm{O}_{y}$, as well. In fact, this can be visually observed in glass/FTO/CdS/CdTe/Au devices. As soon as the devices are made, the $\mathrm{Au}$ 
contacts show a shiny Au color. However, with time, the appearance of the Au contacts shows a dull and $\mathrm{Cu}$ color due to these microscopic interactions at the interface. This effect is shown on both $\mathrm{Au} / \mathrm{bulk} \mathrm{CdTe}$ and $\mathrm{Au} /$ thin films of $\mathrm{CdTe}$ thin films grown using either the $3 \mathrm{E}$ or $2 \mathrm{E}$ systems.

\subsection{CdS/CdTe Solar Cells}

In this research program, both $3 \mathrm{E}$ and $2 \mathrm{E}$ systems were used in parallel to electroplate CdTe from $\mathrm{CdSO}_{4}$ precursor and to fabricate glass/FTO/CdS/CdTe/Au solar cells. Both materials are capable of producing PV active solar cells with varying conversion efficiencies in a wide range of $5 \%-13 \%$. The efficiency differs from batch to batch, and the cell parameters show wide variation.

This wide variation of efficiency is not unique to devices fabricated with electroplated CdTe layers. This seems to be a common feature for devices made by different growth techniques. Therefore, this should be an inherent property of poly-crystallite CdTe and needs deep understanding of this material issue. Since the $\mathrm{CdCl}_{2}$ treatment is a key processing step, full understanding is also essential to understand these efficiency variations. In addition, the existence of pinholes, non-uniformity during growth, different defect concentrations at different points and varying doping concentrations could contribute to this large variation.

In this comprehensive research program carried out over the past two decades, the growth was performed by more than six researchers using the $3 \mathrm{E}$ system. However, the device efficiencies observed were variable, and the highest efficiency observed was $6.9 \%$. Although the efforts devoted to CdTe growths using the $2 \mathrm{E}$ system are less than half that of the $3 \mathrm{E}$ system, the probability of achieving better performance is higher with 2E-grown materials. Table 3 shows the parameters observed for the best solar cells to date using CdTe grown from the $2 \mathrm{E}$ and $3 \mathrm{E}$ systems.

Table 3. Summary of the device parameters obtained from the $I-V$ characteristics for devices fabricated with CdTe grown by the $2 \mathrm{E}$ and $3 \mathrm{E}$ systems.

\begin{tabular}{|c|c|c|c|c|c|c|}
\hline Device Parameter & $\mathbf{R F}$ & $n$ & $I_{0}(\mathrm{nA})$ & $\Phi_{\mathrm{b}}(\mathrm{eV})$ & $R_{\mathrm{S}}(\Omega)$ & $R_{\mathrm{sh}}(\mathrm{M} \Omega)$ \\
\hline \multicolumn{7}{|c|}{ I-V Parameters Measured under Dark Condition } \\
\hline $2 \mathrm{E}$ & 104.3 & 1.88 & 0.79 & $>0.81$ & 1351 & $\rightarrow \infty(81)$ \\
\hline $3 \mathrm{E}$ & 104.7 & 2.40 & 1.00 & $>0.80$ & 277 & $\rightarrow \infty$ (95) \\
\hline Device Parameter & $V_{\text {oc }}(\mathrm{V})$ & $J_{\mathrm{sc}}\left(\mathrm{mA} \cdot \mathrm{cm}^{-2}\right)$ & FF & $\eta(\%)$ & $R_{\mathrm{S}}(\Omega)$ & $R_{\mathrm{sh}}(\Omega)$ \\
\hline \multicolumn{7}{|c|}{ I-V Parameters measured under AM 1.5 illumination } \\
\hline $2 \mathrm{E}$ & 0.670 & 41.5 & 0.46 & 12.8 & 134 & 3819 \\
\hline $3 \mathrm{E}$ & 0.670 & 22.0 & 0.47 & 6.9 & 185 & 5270 \\
\hline
\end{tabular}

The highest efficiency value observed to date for $2 \mathrm{E}$ is $12.8 \%$, as shown in Figure 10 and Table 3. The $I-V$ characteristics of dark and illuminated (AM 1.5) conditions for a device with CdTe grown by the 2E system are shown in Figure 10. This structure also has a thin layer $(100 \mathrm{~nm})$ of $\mathrm{n}-\mathrm{ZnS}$ as a buffer layer, forming a three-layer graded bandgap device. All possible device properties have been extracted from these $I-V$ characteristics and summarized in Table 3 . These excellent properties, including very high short circuit current densities, show the high potential of graded bandgap device structures [36,37]. These high efficiencies have been observed for CdTe materials grown using $2 \mathrm{E}$ systems. Although it is pre-mature to draw a firm conclusion, materials grown from $2 \mathrm{E}$ systems are comparable, if not superior to those grown from $3 \mathrm{E}$ systems. 


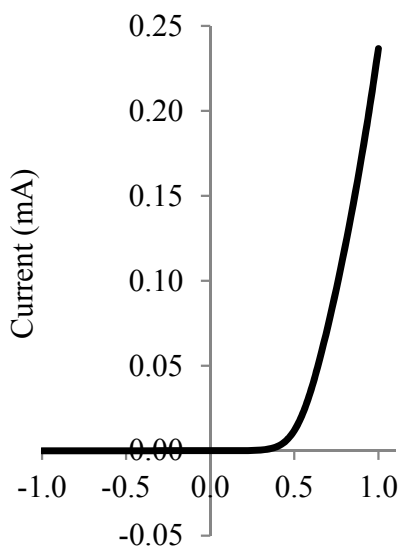

Bias Voltage (V)

(a)

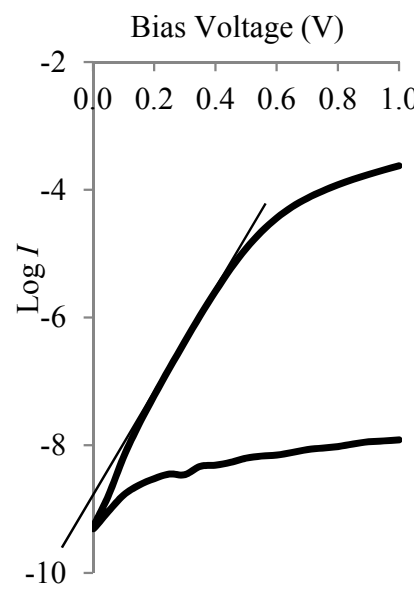

(b)

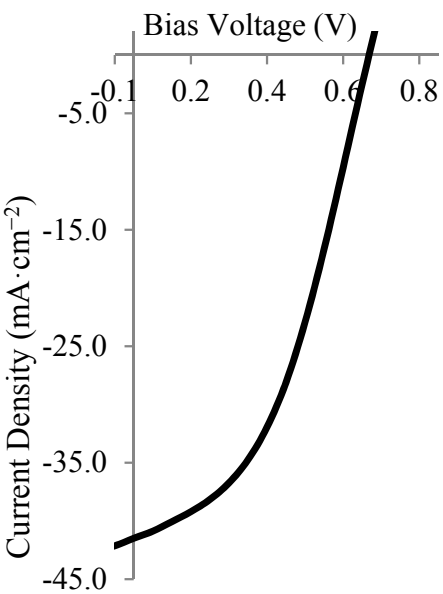

(c)

Figure 10. Typical $I-V$ characteristics observed for the glass/FTO/n-ZnS/n-CdS/n-CdTe/Au device with CdTe layers grown using the 2E system. (a) Linear-linear $I-V \&$ (b) Log-Linear $I-V$ under dark condition, and (c) Linear-linear $I-V$ under AM 1.5 illumination condition.

\section{Conclusions}

The results presented in this paper lead to the drawing of several conclusions.

- $\quad$ Both 3E and 2E systems produce CdTe layers with similar structural properties. CdTe material is poly-crystalline, with a cubic crystal structure and grown with a (111) preferential orientation. The only difference observed is the higher growth rate when the 2E system is used, and this is an added advantage in a production line.

- The morphologies of the CdTe layers are very similar. In as-deposited layers, the FTO substrate is covered by large CdTe agglomerations, consisting of small crystallites. The sizes of the crystallites vary from 20 to $65 \mathrm{~nm}$, as estimated by XRD measurements. Upon $\mathrm{CdCl}_{2}$ treatment, these crystallites merge into large crystals ranging in the few microns size. Then, the layers are comparable with materials grown by high temperature techniques, such as closed-space sublimation. IPL treatment provides a convenient rapid thermal annealing method suitable for flexible substrates and roll-to-roll production methods. SEM images also indicate the melting of grain boundary regions during heat-treatment in the presence of $\mathrm{CdCl}_{2}$.

- CdTe layers grown from both methods seem to have elemental Te as precipitates or a surface layer. $\mathrm{CdCl}_{2}$ treatment removes this excessive Te and makes the material more stoichiometric. Comprehensive device work also shows that Te richness is detrimental for devices, and stoichiometric or Cd-rich CdTe is more suitable for enhanced device performance.

- $\quad$ Both the 3E and 2E systems allow the growth of p- and n-type CdTe layers. Te richness produces p-type material, and $\mathrm{Cd}$ richness produces n-type $\mathrm{CdTe}$. Both methods produce high crystallinity at the perfect point of stoichiometry (PPS), and the energy bandgap measured for stoichiometric material is close to the bandgap of bulk CdTe $(1.45 \mathrm{eV})$.

- $\quad$ PL spectra of CdTe layers grown from the $3 \mathrm{E}$ and $2 \mathrm{E}$ systems have similar fingerprints. $\mathrm{CdCl}_{2}$ treatment shows the reduction of some defects, and the materials arising from the $2 \mathrm{E}$ system show improved quality in terms of defect concentrations.

- UPS results summarized and soft-XPS results reported before show a strong intermixing at the $\mathrm{CdTe} / \mathrm{Au}$ interface. This may lead to the degradation of devices, and therefore, a reaction barrier should be introduced in order to improve the stability and lifetime of the devices. 
- From a large amount of device fabrication experience, both CdTe layers grown by the $3 \mathrm{E}$ and $2 \mathrm{E}$ systems show wide variation of the efficiency values between $5 \%$ and $13 \%$. Although premature to draw firm conclusions, the highest efficiency values observed to date in our research laboratories have been fabricated using CdTe layers grown by the $2 \mathrm{E}$ system. Therefore, the elimination of a possible impurity source (reference electrode) introduces several advantages, such as improving the growth rate, system simplification, cost reduction and ability to grow improved materials at elevated temperatures and, hence, the fabrication of comparable or better performing devices.

Acknowledgments: Authors would like to thank A.P. Samantilleke, Nandu Chaure, G. Muftah, Jayne Wellings, N. A. Abdul-Manaf, A.A. Ojo and H.I. Salim for their contributions to this work.

Author Contributions: SHU-Solar Energy Group members (Imyhamy M. Dharmadasa, Mohammad L. Madugu and Olajide I. Olusola): conceived of the work and did the design and the writing of the paper, the electrodeposition of CdS and CdTe, materials' characterization, device fabrication and assessment, interpretation of the results, understanding the science behind the materials and devices, the drafting of the manuscript, the drawing of diagrams and the completion of the paper. Obi K. Echendu, Fijay Fauzi, Dahiru G. Diso and Ajith R. Weerasinghe: The development of the materials and optimization. Conn Center for Renewable Energy Research, University of Louisville, Louisville, Kentucky 40292, USA Group members (Thad Druffel, Ruvini Dharmadasa, Brandon Lavery, Jacek B. Jasinski, Tatiana A. Krentsel and Gamini Sumanasekera): Carried out the photoluminescence (PL) experiment and analysis.

Conflicts of Interest: The authors declare no conflicts of interest.

\section{References}

1. Basol, B.M. High-efficiency electroplated heterojunction solar cell. J. Appl. Phys. 1984, 55, 601-603. [CrossRef]

2. Gnatenko, Y.P.; Bukivskij, P.M.; Opanasyuk, S.; Kurbatov, D.I.; Kolesnyk, M.M.; Kosyak, V.V.; Khlyap, H. Low-temperature photoluminescence of II-VI films obtained by close-spaced vacuum sublimation. J. Lumin. 2012, 132, 2885-2888. [CrossRef]

3. Dharmadasa, I.M. Recent developments and progress on electrical contacts to CdTe, CdS and ZnSe with special reference to barrier contacts to CdTe. Prog. Cryst. Growth Charact. Mater. 1998, 36, 249-290. [CrossRef]

4. Bube, R.H. Photovoltaic Materials; Newman, R.C., Ed.; Imperial College Press: London, UK, 1998.

5. Takahashi, M.; Uosaki, K.; Kita, H.; Suzuki, Y. Effects of heat treatment on the composition and semiconductivity of electrochemically deposited CdTe films. J. Appl. Phys. 1985, 58, 4292. [CrossRef]

6. Chaure, N.B.; Samantilleke, A.P.; Dharmadasa, I.M. The effects of inclusion of iodine in CdTe thin films on material properties and solar cell performance. Sol. Energy Mater. Sol. Cells 2003, 77, 303-317. [CrossRef]

7. Dharmadasa, I.M.; Bingham, P.A.; Echendu, O.K.; Salim, H.I.; Druffel, T.; Dharmadasa, R.; Sumanasekera, G.U.; Dharmasena, R.R.; Dergacheva, M.B.; Mit, K.A.; et al. Fabrication of CdS/CdTe-Based thin film solar cells using an electrochemical technique. Coatings 2014, 4, 380-415. [CrossRef]

8. Panthani, M.G.; Kurley, J.M.; Crisp, R.W.; Dietz, T.C.; Ezzyat, T.; Luther, J.M.; Talapin, D.V. High efficiency solution processed sintered CdTe nanocrystal solar cells: The role of interfaces. Nano Lett. 2014, 14, 670-675. [CrossRef] [PubMed]

9. Sugiyama, K. Properties of CdTe films grown on InSb by molecular beam epitaxy. Thin Solid Films 1984, 115, 97-107. [CrossRef]

10. Mora-Seró, I.; Tena-Zaera, R.; González, J.; Muñoz-Sanjosé, V. MOCVD growth of CdTe on glass: Analysis of in situ post-growth annealing. J. Cryst. Growth 2004, 262, 19-27. [CrossRef]

11. Ghosh, B.; Hussain, S.; Ghosh, D.; Bhar, R.; Pal, A.K. Studies on CdTe films deposited by pulsed laser deposition technique. Phys. B Condens. Matter 2012, 407, 4214-4220. [CrossRef]

12. Panicker, M.P.R. Cathodic deposition of CdTe from aqueous electrolytes. J. Electrochem. Soc. 1978, 125, 566. [CrossRef]

13. Pandey, R.K.; Sahu, S.B.; Chandra, S. Handbook of Semiconductor Electrodepotion; Marcel Dekker, Inc.: New York, NY, USA, 1996.

14. Abdul-Manaf, N.; Salim, H.; Madugu, M.; Olusola, O.; Dharmadasa, I. Electro-plating and characterisation of CdTe thin films using $\mathrm{CdCl}_{2}$ as the cadmium source. Energies 2015, 8, 10883-10903. [CrossRef]

15. Arai, K.; Kawaguchi, J.; Murase, K.; Hirato, T.; Awakura, Y. Effect of chloride ions on the electrodeposition behavior of CdTe from ammoniacal basic electrolytes. J. Surf. Finish. Soc. Jpn. 2006, 57, 70-76. [CrossRef] 
16. Bhattacharya, R.N.; Rajeshwar, K. Heterojunction CdS/CdTe solar cells based on electrodeposited p-CdTe thin films: Fabrication and characterization. J. Appl. Phys. 1985, 58, 3590-3593. [CrossRef]

17. Lincot, D. Electrodeposition of semiconductors. Thin Solid Films 2005, 487, 40-48. [CrossRef]

18. Cunningham, D.; Rubcich, M.; Skinner, D. Cadmium telluride PV module manufacturing at BP Solar. Prog. Photovolt. Res. Appl. 2002, 10, 159-168. [CrossRef]

19. Salim, H.I.; Patel, V.; Abbas, A.; Walls, J.M.; Dharmadasa, I.M. Electrodeposition of CdTe thin films using nitrate precursor for applications in solar cells. J. Mater. Sci. Mater. Electron. 2015, 26, 3119-3128. [CrossRef]

20. First Solar's Cells Break Efficiency Record. Available online: https:/ /www.technologyreview.com/s/600922/ first-solars-cells-break-efficiency-record (accessed on 19 January 2016).

21. Dennison, S. Dopant and impurity effects in electrodeposited CdS/CdTe thin films for photovoltaic applications. J. Mater. Chem. 1994, 4, 41-46. [CrossRef]

22. Echendu, O.K.; Okeoma, K.; Oriaku, C.I.; Dharmadasa, I.M. Electrochemical deposition of CdTe semiconductor thin films for solar cell application using two-electrode and three-electrode configurations: A comparative study. Adv. Mater. Sci. Eng. 2016, 2016, 3581725. [CrossRef]

23. Dharmadasa, R.; Lavery, B.W.; Dharmadasa, I.M.; Druffel, T. Processing of CdTe thin films by intense pulsed light in the presence of $\mathrm{CdCl}_{2}$. J. Coat. Technol. Res. 2015, 12, 835-842. [CrossRef]

24. Diso, D.G. Research and Development of CdTe Based Thin Film PV Solar Cells. Ph.D. Thesis, Sheffield Hallam University, Sheffield, UK, 2011.

25. Dharmadasa, I.M.; Ehendu, O.K.; Fauzi, F.; Abdul-Manaf, N.A.; Olusola, O.I.; Salim, H.I.; Madugu, M.L.; Ojo, A.A. Improvement of composition of CdTe thin films during heat treatment in the presence of $\mathrm{CdCl}_{2}$. J. Mater. Sci. Mater. Electron. 2016. [CrossRef]

26. Cheung, J.T. Role of atomic tellurium in the growth kinetics of CdTe (111) homoepitaxy. Appl. Phys. Lett. 1987, 51, 1940-1942. [CrossRef]

27. Fernandez, P. Defect structure and luminescence properties of CdTe based compounds. J. Optoelectron. Adv. Mater. 2003, 5, 369-388.

28. Dharmadasa, I.M.; Echendu, O.K.; Fauzi, F.; Abdul-Manaf, N.A.; Salim, H.I.; Druffel, T.; Dharmadasa, R.; Lavery, B. Effects of $\mathrm{CdCl}_{2}$ treatment on deep levels in CdTe and their implications on thin film solar cells: A comprehensive photoluminescence study. J. Mater. Sci. Mater. Electron. 2015, 26, 4571-4583. [CrossRef]

29. Dharmadasa, I.M.; Thornton, J.M.; Williams, R.H. Effects of surface treatments on Schottky barrier formation at metal/n-type CdTe contacts. Appl. Phys. Lett. 1989, 54, 137-139. [CrossRef]

30. Sobiesierski, Z.; Dharmadasa, I.M.; Williams, R.H. Correlation of photoluminescence measurements with the composition and electronic properties of chemically etched CdTe surfaces. Appl. Phys. Lett. 1988, 53, 2623-2625 [CrossRef]

31. Dharmadasa, I.M. Advances in Thin-Films Solar Cells; Pan Stanford Publishing Pte Ltd.: Singapore, 2012.

32. Dharmadasa, I.M.; Echendu, O.K.; Fauzi, F.; Salim, H.I.; Abdul-Manaf, N.A.; Jasinski, J.B.; Sherehiy, A.; Sumanasekera, G. Study of fermi level position before and after $\mathrm{CdCl}_{2}$ treatment of $\mathrm{CdTe}$ thin films using ultraviolet photoelectron spectroscopy. J. Mater. Sci. Mater. Electron. 2016. [CrossRef]

33. Handbook of Chemistry and Physics; CRC Press: Cleveland, OH, USA, 1977.

34. Okuyama, K.; Tsuhako, J.; Kumagai, Y. Behavior of metal contacts to evaporated tellurium films. Thin Solid Films 1975, 30, 119-126. [CrossRef]

35. Forsyth, N.M.; Dharmadasa, I.M.; Sobiesierski, Z. An investigation of metal contacts to II-VI compounds: CdTe and CdS. Vacuum 1988, 38, 369-371. [CrossRef]

36. Dharmadasa, I.M.; Ojo, A.; Salim, H.; Dharmadasa, R. Next generation solar cells based on graded bandgap device structures utilising rod-type nano-materials. Energies 2015, 8, 5440-5458. [CrossRef]

37. Echendu, O.; Dharmadasa, I.M. Graded-bandgap solar cells using all-electrodeposited ZnS, CdS and CdTe thin Ffilms. Energies 2015, 8, 4416-4435. [CrossRef]

(C) 2017 by the authors; licensee MDPI, Basel, Switzerland. This article is an open access article distributed under the terms and conditions of the Creative Commons Attribution (CC BY) license (http:/ / creativecommons.org/licenses/by/4.0/). 